\title{
Role of Media on Social Health of Elderly in Durg Bhilai City
}

\author{
Rajshree Chandrakar, Dr. A. Joglekar \\ Bhilai Mahila Mahavidayalya Bhilai, Govt. D.B.P.G Girls College, Raipur, Chhattisgarh, India
}

\begin{abstract}
Elderly suffers from various problems in our society, because of lack of communication. Media is a strong communication tool which can be easily approached. To make elderly people socially healthy media play an important role, hence a randomized prospective survey was conducted. The objective of this study was to investigate the role of media on social health of elderly. The study was conducted in 40 elderly residing in Durg-Bhilai province. 20 male 20 female were selected. A self designed questionnaire was used to collect the data. The obtained data were analyzed by percentage. Among all types of media, mobile was used for conversation by $80 \%$ male and $70 \%$ female, and to maintain a healthy relationship both $65 \%$ male and female used it. The findings revealed that social media (friends and groups) played a positive role to boost the social health of elderly.
\end{abstract}

Keywords: Elderly, media, social health

\section{Introduction}

Ageing is a phase of life and biological phenomena. It brings a lot of Anatomical, Physiological and Psychological changes in life. (Chadha and chao 2006). It is a stage wherein a person gets rid of all the responsibilities. The Government of India adopted National policy on older person defines "senior citizen" or "elderly" as a person who is of age 60 years and above. (Jan 1999).Our society is moving towards an aging population.

It has been estimated that by $21^{\text {st }}$ century majority of population in both developed and developing countries will be elder ones. In 1991 the grey population which accounted for $67 \%$ of total population is expected to increase more than $10 \%$ till 2021. (Govt of India 2011).The increase in medical facility and better living standards has further lengthened the life span of individuals and hence simultaneously increased the aged population.

Due to urbanization, mechanization, modernization globalization and family nuclearization in our society nobody has time to communicate with elderly. Life is full of stress factors like financial strain, loss of loved ones, due to this elderly suffers from various psychosocial problems like loneliness, depression stress and social disconnectedness etc. In order to cope from this problems media has played a very pivotal role. Elderly from western countries are more dependent on media to cope up with psychosocial problems. Media like mobile, Television, newspaper, and social media(Friends, groups, clubs, community activities) are the tools frequently used by elderly. It has always remained a very strong means of communication and helps in transferring and acquiring information. Jurate Sucylate (2004) thought that communication will free everyone from problems determined system and improve the quality of life. Faber J.A (2004) suggested that reality is an intersubjective phenomenon i.e. most of the problems can be solved through conversation. The WHO (2002) has proposed a model of active ageing base on optimizing opportunities for health participation in order to enhance the quality of life. In India elderly are considered as the honorable and respectable person. There is a dearth of literature which describes the role of media which make the elderly socially healthy and hence the need of study.

\section{Methodology}

A survey has been conducted in the Durg-Bhilai city of Chattisgarh state with a basic objective to determine the role of media on social health of elderly. A total of 40 sample, 20 male and 20 female of age groups 60 years and above were selected from middle income group. A self designed questionnaire was distributed; elderly shared their views and attitude about different types of media i.e. Newspaper, Television (T.V), Mobile and Social media (Friends, Group, Club).

\section{Results and Discussion}

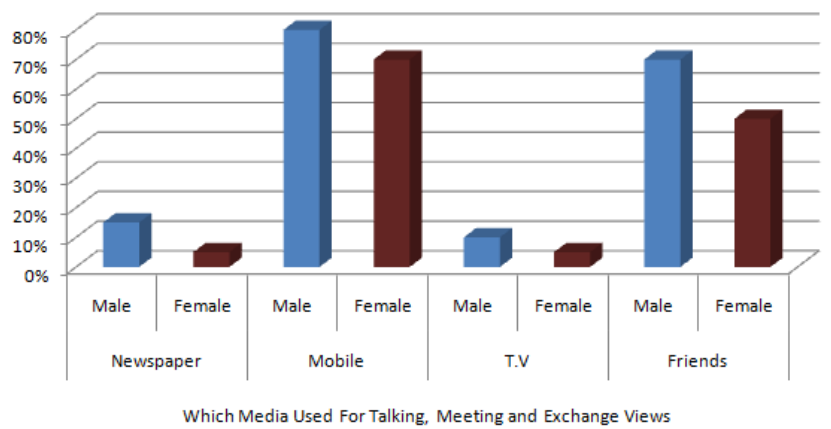

1. For the above purpose it was found that $80 \%$ male and $70 \%$ female elderly used mobile which was followed by group formation, news paper and TV. 


\section{International Journal of Science and Research (IJSR) \\ ISSN (Online): 2319-7064}

Index Copernicus Value (2013): 6.14 | Impact Factor (2015): 6.391

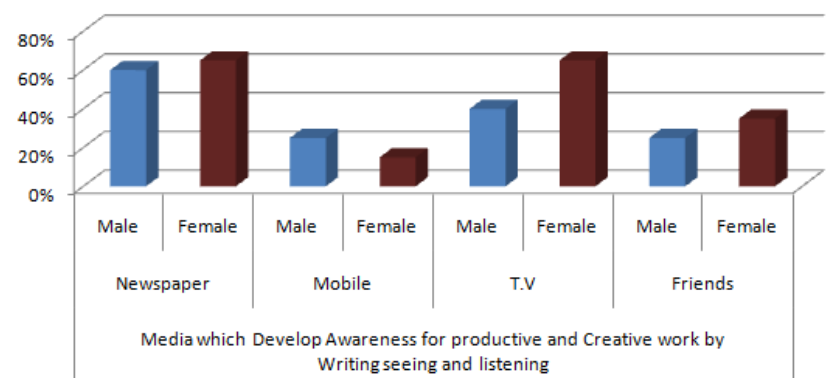

2. For the above criteria $60 \%$ male and $65 \%$ female used newspaper followed by T.V, friend's formation and mobile.

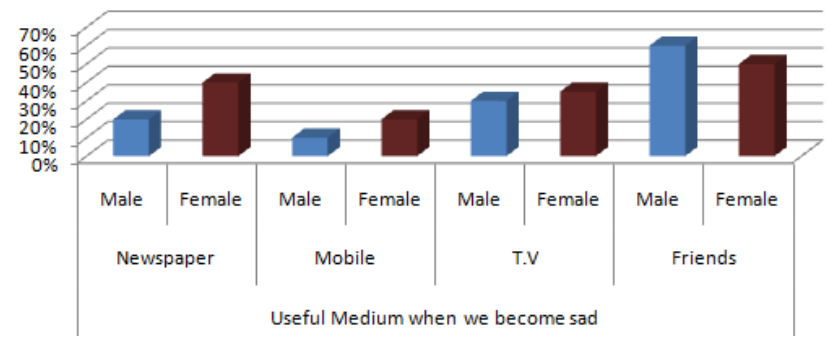

3. For the above purpose it was found that $60 \%$ male and $50 \%$ female prefer friends, groups and institution followed by TV newspaper and mobile. Research suggests that engagement in meaningful productive activities, often within the context of friendship, kinship, and organizational participation, is a key component in promoting health and reducing the risk of mortality in later life (Rowe \& Kahn, 1998).

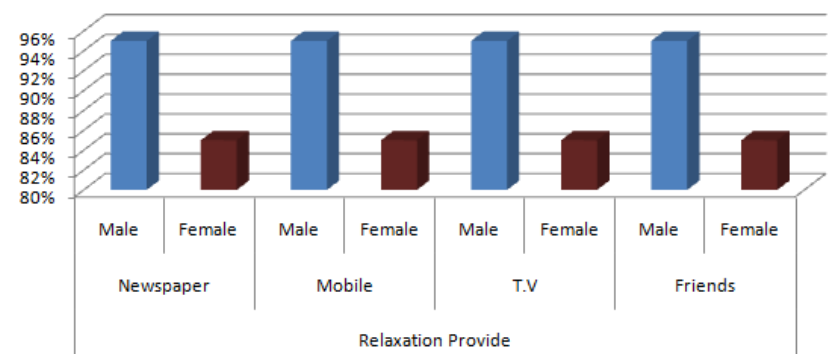

4. For the above it was found that $95 \%$ male and $85 \%$ female prefer all types of media.

It was observed by Sucylaite J (2014) that sharing positive memories tends to release tension and gives a feeling of relaxation.

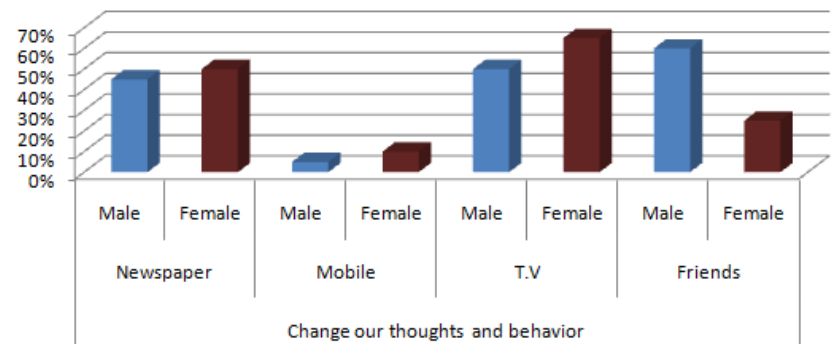

5. For the above criteria it was found that $65 \%$ of female and $50 \%$ male used TV followed by friends, newspaper and mobile.

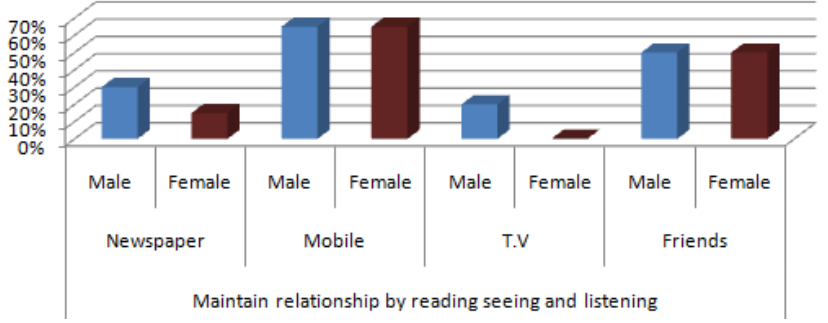

6. For the above purpose $65 \%$ male an $65 \%$ female used mobile which was followed by friends and group, newspaper and TV.

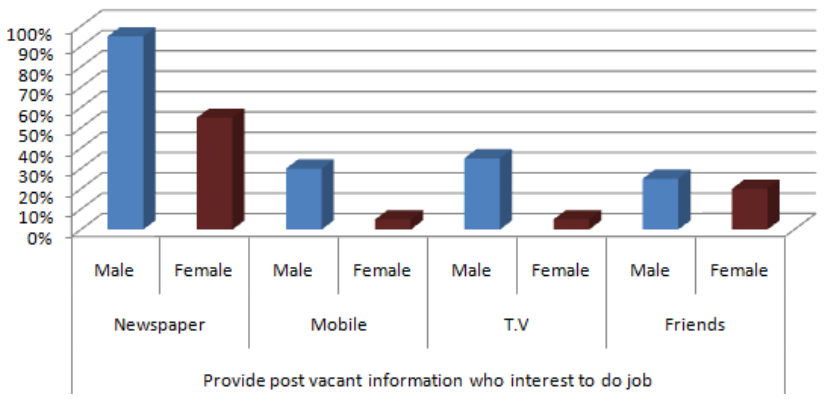

7. For the above purpose $95 \%$ male and $55 \%$ female prefer newspaper followed by TV, mobile, friends and group.

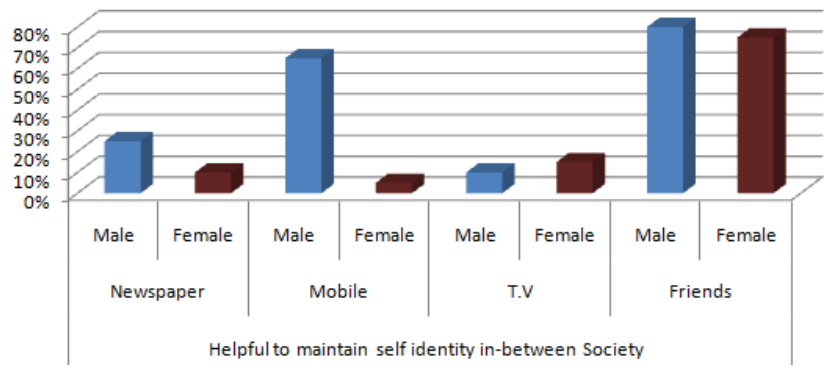

8. It was found that $80 \%$ male and $75 \%$ female use friends and group which were followed by mobile, newspaper and TV.

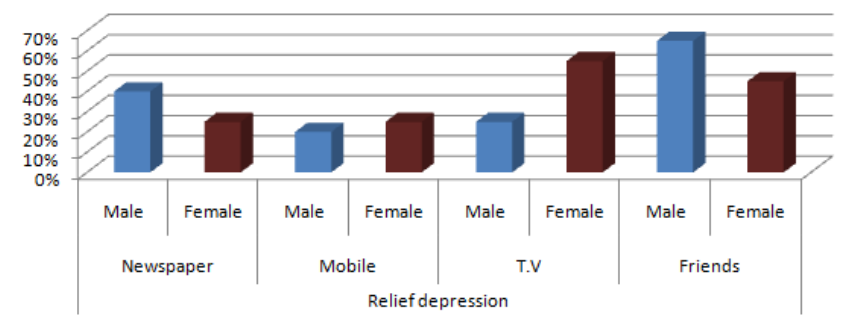

9. For the above purpose it was found that $65 \%$ male and $45 \%$ female elderly prefer friend, relative and groups followed by newspaper TV and mobile.

Stevens N and Van Tilburg T (2000) suggested that there are different types of friendship and complex network might be the best protection against loneliness and reduce depression.

\section{Volume 5 Issue 6, June 2016 www.ijsr.net}




\section{International Journal of Science and Research (IJSR) \\ ISSN (Online): 2319-7064}

Index Copernicus Value (2013): 6.14 | Impact Factor (2015): 6.391

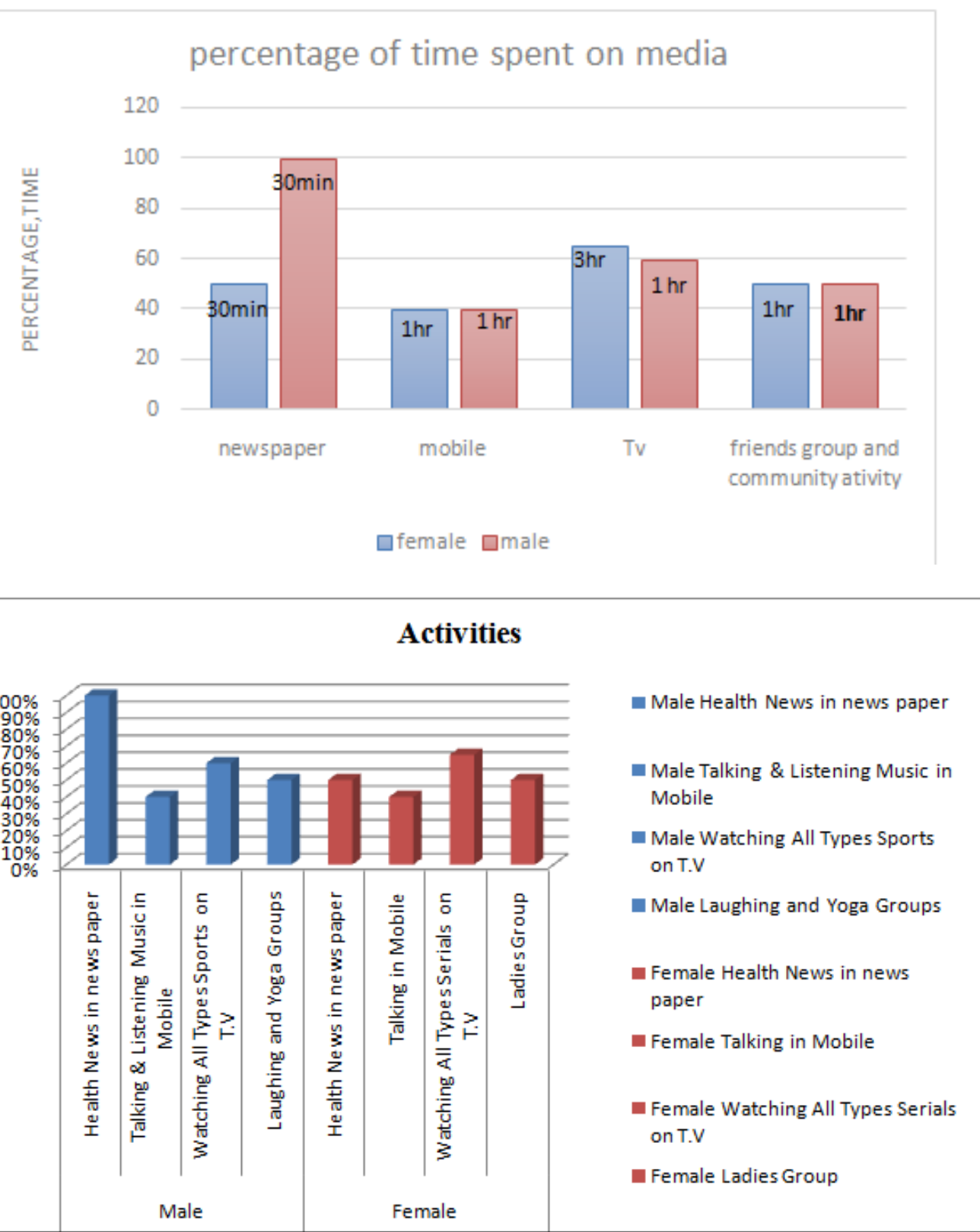

\section{Conclusion}

Media is one of the strongest means of communication. Most of the elderly used media for conversation, relaxation, maintain relationship and self identification etc. They were more happy with their friends, groups and community through various activities e.g. yoga, walking, kitty parties (B.C) and other religious activities (Bhajan, Ramayan and Satsang). From the above results it can be concluded that media made the elderly people socially healthy. It became inseperable part of their lives. Regarding awareness it was observed that male were more aware about media than females. Training and counseling were needed for females for mobile handling, internet, twitter, Facebook and wats app etc.. But further research is recommended.

\section{References}

[1] Situation analysis of the elderly in India. (2011) Central statistics Office ministry of statistics and program implementation. Government of India. pg. 3

[2] Chadha and Chao(2006)Shodhganga.inflibnet.ac.in/bitstream/1063 /32727/.../07_chapter\%201.p

[3] Faber J.A (2004) Therapy with the elderly. Journal of family Psychotherapy 14:4, 1-14.

[4] Stevens N and Van Tilburg T (2000) Stimulating friendship in later life a strategy for reducing loneliness among older women. Educational Gerontology $26: 1,15-36$

[5] Sucylaite Jurate(2014) “ Elderly people communication in literature learning Environment" Elseiver http/ creative commons.org/licence/ncnc/4.01.

[6] Rowe, J. R., \& Kahn, R. L. (1998). Successful aging. New York: Pantheon Books 